\title{
Palm H-FAME Production through Partially Hydrogenation using Nickel/Carbon Catalyst to Increase Oxidation Stability
}

\author{
Elsa Ramayeni ${ }^{1}$, Bambang Heru Susanto ${ }^{1, *}$, and Dimas Firlyansyah Pratama ${ }^{1}$ \\ ${ }^{1}$ Chemical Engineering Department, Faculty of Engineering, University of Indonesia, Depok 16424, Indonesia
}

\begin{abstract}
One of the methods to improve the oxidation stability of palm biodiesel is through partially hydrogenation. The production using Nickel/Carbon catalyst to speed up the reaction rate. Product is called Palm H-FAME (Hydrogenated FAME). Partial hydrogenation breaks the unsaturated bond on FAME (Fatty Acid Methyl Ester), which is a key component of the determination of oxidative properties. Changes in FAME composition by partial hydrogenation are predicted to change the oxidation stability so it does not cause deposits that can damage the injection system of diesel engine, pump system, and storage tank. Partial hydrogenation is carried out under operating conditions of $120^{\circ} \mathrm{C}$ and 6 bar with $100: 1,100: 3,100: 5,100: 10 \% \mathrm{wt}$ catalyst in the stirred batch autoclave reactor. H-FAME synthesis with 100:5\% wt Ni/C catalyst can decrease the iodine number which is the empirical measure of the number of unsaturated bonds from 91.78 to $82.38\left(\mathrm{~g}-\mathrm{I}_{2} / 100 \mathrm{~g}\right)$ with an increase of oxidation stability from 585 to 602 minutes.
\end{abstract}

\section{Introduction}

High quality biodiesel will generate many benefit. The advantage of biodiesel is environmentally friendly emissions because it does not contain $\mathrm{SO}_{2}$ and has a good lubrication effect. Biodiesel is defined as a fuel consisting of mono alkyl esters of long chain fatty acids derived from vegetable oils and animal oils. Biodiesel is produced by a process of transesterification reaction by reacting vegetable oil or animal fat catalytically with short chain aliphatic alcohols that produce FAME (Fatty Acid Methyl Ester) and glycerol as byproducts [1].

Biodiesel is a biofuel that reduces the level of exhaust emissions. In addition, biodiesel mixes perfectly with diesel oil (Solar) and works well on all types of diesel engines. The main biodiesel advantage is that engine modifications are not required to run diesel engines. To ensure the quality of biodiesel, Indonesia has implemented the National Standard SNI 04-7182-2006 which was first ratified in 2006 and revised in 2015 with changes in the value of several parameters.

In fact, biodiesel that has passed through the production process can be degraded into other compounds that result in changes of biodiesel components during the storage process even though the biodiesel meets the established standards. These changes happen because biodiesel is very easily degraded into compounds such as acids, aldehydes, ketones, esters, peroxides and alcohols [2]. Changes in the characteristics of biodiesel caused by the oxidation process include increasing the viscosity value, peroxide number, acid number and decreasing the induction period [3].

Pertamina currently produces Biosolar with 15\% biodiesel and $85 \%$ of diesel. Furthermore, the government hopes to increase biodiesel percentage by up to $30 \%$. However, this mixture should be further investigated because the mixture results in a low biodiesel oxidation stability effect in which diesel engines are adversely affected by the emergence of deposits and gums that would damage the injection system, pumping systems and storage tanks.

The oxidation process of biodiesel is influenced by long acid chain fatty acids $\left(\mathrm{C}_{16}\right.$ to $\left.\mathrm{C}_{24}\right)$ which contain unsaturated compounds that have lower oxidation stability value. Therefore, to improve the oxidation stability, it is necessary to modify the biodiesel component (FAME). One way that can be done is by a partial hydrogenation reaction in which the reaction will break the unsaturated bond on FAME which is a key component of the determination of oxidative properties. Changes in the composition of FAME will change the oxidation stability, cetane number, and biodiesel viscosity [4].

On the other hand, palm oil is the most reliable as biodiesel feedstock because palm biodiesel has low FFA (Free Fatty Acid) $(<5 \%)$, therefore in biodiesel synthesis only through transesterification reaction. In addition, the main components of palm oil biodiesel are methyl palmitate (18:0) and methyl oleate (18: 1), both of these

\footnotetext{
*orresponding author: bambanghs@,che.ui.ac.id
} 
components exhibit very low saturation bonds so that biodiesel is not easily oxidized and has good cetane index. Thus, this study was conducted to prove that the oxidation stability of the product is increased through the partial hydrogenation of the FAME component with the source of the biodiesel feedstock from palm oil.

\section{Methodology}

\subsection{Materials}

This study was conducted in two steps namely the synthesis of H-FAME in a hydrogenation reactor and characterization of H-FAME product. The materials needed in this study were: Palm Biodiesel (Wilmar), $\mathrm{Ni} / \mathrm{C}$ (Pratama), Aquadest (CV. Dwinika), Chloroform (Merck), Wijs (Merck), Sodium Thiosulfate (Merck), Potassium Iodide (Merck), Starch (Merck), Potassium Hydroxide (Merck), Phenolphthalein (Merck).

\subsection{Partially Hydrogenated FAME}

The reaction was performed in a $250 \mathrm{~mL}$ batch stirred reactor integrated with a condenser and furnace. Extensive stirring of the biodiesel and catalyst in the reactor was accomplished using a magnetically driven, stirred with a DC geared motor. $\mathrm{Ni} / \mathrm{C}$ catalyst was purged using nitrogen for 30 minutes, and then the $\mathrm{Ni} / \mathrm{C}$ catalyst was activated by hydrogen at 10 bar and $400{ }^{\circ} \mathrm{C}$ for 1 hour. Palm FAME was used as feed and $\mathrm{Ni} / \mathrm{C}$ catalyst with variation ratio of 100:1, $100: 3,100: 5$, and $100: 10 \%$ wt. Before the hydrogenation, the feed and the catalyst were purged using nitrogen to remove $\mathrm{O}_{2}$ for 30 minutes. Stirring speed and pressure during the reaction were kept constantly at $200 \mathrm{rpm}$ and 6 bar respectively. The reactions were performed at temperature $120^{\circ} \mathrm{C}$ for 2.5 hours. In this step, the double bonds that were presented in the FAME were saturated with hydrogen. Figure 1 shows a schematic diagram of the apparatus.

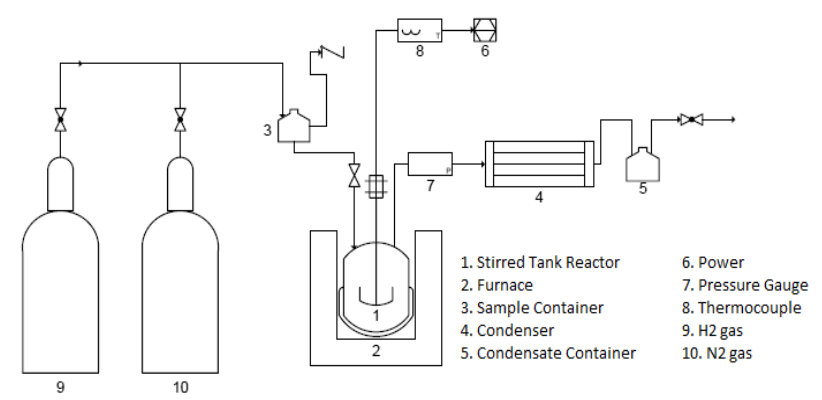

Fig. 1. Scheme of Hydrogenation Reaction

The product is characterized by iodine number test to determine the double bond reduction, acid number test to determine the amount of free fatty acid in the biodiesel, FT IR (Thermo Scientific) to know the effect of reaction to the presence of functional group in FAME, GCMS (Agilent Technologies) to identify components of sample, and oxidation stability test to determine the increased oxidative stability. Furthermore, the product is characterized by the density, viscosity, and cetane index to examine quality of combustion of the product.

\section{Result and Discussion}

The used catalyst was Nickel/Carbon. In test variations, the catalyst was activated first. A physical properties result of the catalyst that had been used in H-FAME synthesis is attached in Table 3.1.

Table 3.1 Physical Properties of Catalyst Used

\begin{tabular}{|c|c|c|c|}
\hline Catalyst & $\begin{array}{c}\text { Surface Area } \\
\left(\mathrm{m}^{2} / \text { gram }\right)\end{array}$ & $\begin{array}{c}\text { Pore Size } \\
(\mathrm{nm})\end{array}$ & $\begin{array}{c}\text { Crystal } \\
\text { Size } \\
(\mathrm{nm})\end{array}$ \\
\hline $\mathrm{Ni} / \mathrm{C}$ & 285.85 & 2.2 & 77.78 \\
\hline
\end{tabular}

To facilitate an explanation of the characterization results of the H-FAME samples in the next section, the researcher made a standard naming sample based on the amount of the catalyst used on the reaction, presented in Table 3.2.

Table 3.2 Naming and Sample Operating Conditions

\begin{tabular}{|c|c|}
\hline Products & $\mathrm{Ni} / \mathrm{C}(\% \mathrm{wt})$ \\
\hline H-FAME a & $100: 1$ \\
\hline H-FAME b & $100: 3$ \\
\hline H-FAME c & $100: 5$ \\
\hline H-FAME d & $100: 10$ \\
\hline
\end{tabular}

\subsection{Result of Characterization}

Result of chemical characterization of H-FAME product can be seen in Table 3.3.

Table 3.3 Chemical Properties of H-FAME

\begin{tabular}{|c|c|c|c|}
\hline Product & $\begin{array}{c}\text { Iodine } \\
\text { Number } \\
\left(\mathrm{g}-\mathrm{I}_{2} / 100 \mathrm{~g}\right)\end{array}$ & $\begin{array}{c}\text { Oxidation } \\
\text { Stability } \\
\text { (minute) }\end{array}$ & $\begin{array}{c}\text { Acidity } \\
\text { Number } \\
(\mathrm{mg}- \\
\mathrm{KOH} / \mathrm{g})\end{array}$ \\
\hline B100 & 91.78 & 585 & 0.33 \\
\hline H-FAME a & 87.21 & - & 0.30 \\
\hline H-FAME b & 86.19 & - & 0.30 \\
\hline H-FAME c & 82.38 & 602 & 0.26 \\
\hline H-FAME d & 80.64 & - & 0.25 \\
\hline SNI 2015 & Max. 115 & Min. 480 & Max. 0.5 \\
\hline
\end{tabular}

Based on Table 3.3, the iodine number decreased with the increasing of the amount of catalyst used. The highest decrease in iodine number was in the catalyst ratio of 100:5 \%wt. The decreasing of iodine number showed a reduction in the number of double bonds in the FAME component.

The oxidation stability characteristic was only performed on H-FAME $\mathrm{c}$ and Palm FAME (B100). It was based on the decreasing of the highest iodine number. The oxidation stability of B100 were examined to know the initial data before the partial hydrogenation 
process. Based on the Table 3.3, it was proved that the partial hydrogenation reaction could increase the oxidation stability of biodiesel.

Table 3.4 Identification of Functional Groups on HFAME Product

\begin{tabular}{|c|c|c|c|c|}
\hline \multirow{2}{*}{ Bonds } & $\begin{array}{c}\text { Functional } \\
\text { Groups }\end{array}$ & $\begin{array}{c}\text { Wave } \\
\text { Number } \\
\left(\mathrm{cm}^{-1}\right)\end{array}$ & B100 & $\begin{array}{c}\text { H-FAME } \\
\mathrm{c}\end{array}$ \\
\hline$=\mathrm{CH}_{2}$ & Alkene & $991-723$ & $\sqrt{ }$ & $\sqrt{ }$ \\
\hline $\mathrm{C}-\mathrm{O}$ & Alcohol & $1169-1243$ & $\sqrt{ }$ & $\sqrt{ }$ \\
\hline $\mathrm{C}=\mathrm{O}$ & Carbonyl & 1740 & $\sqrt{ }$ & $\sqrt{ }$ \\
\hline \multirow{2}{*}{$\mathrm{C}-\mathrm{H}$} & Alkane & $1360-1459$ & $\sqrt{ }$ & $\sqrt{ }$ \\
\cline { 2 - 5 } & Alkane & $2853-2932$ & $\sqrt{ }$ & $\sqrt{ }$ \\
\hline
\end{tabular}

Identification of functional groups using FTIR indicated that the partial hydrogenation reaction did not break the functional group bond but only broke the double bond of the FAME component which was a key component of oxidative properties.

Table 3.5 Component Identification of Sample B100 and H-FAME c

\begin{tabular}{|c|c|c|}
\hline Components & B100 & $\begin{array}{c}\text { H-FAME } \\
\mathrm{c}\end{array}$ \\
\hline \% Methyl Palmitate (18:0) & 33.17 & 33.29 \\
\hline \% Methyl Stearate (18:0) & 9.78 & 9.80 \\
\hline \% Methyl Oleate (18:1) & 38.63 & 39.81 \\
\hline \% Methyl Linoleate (18:2) & 0.28 & 0.20 \\
\hline \% Methyl Linolenate (18:3) & 0.23 & 0.14 \\
\hline
\end{tabular}

According to Table 3.5, the percentage of Methyl Linoleate and Methyl Linolenate components were decreased, while the components of Methyl Oleate, Methyl Stearate, and Methyl Palmitate were increased. These results indicated that the partial hydrogenation reaction had broken the saturated bond on the FAME component into an unsaturated bond. These results also confirmed the result of the decrease in iodine number.

Table 3.6 Physical Properties of H-FAME

\begin{tabular}{cccc}
\hline Sampel & $\begin{array}{c}\text { Density } \\
\left(\mathrm{kg} / \mathrm{m}^{3}\right)\end{array}$ & $\begin{array}{c}\text { Viscosity } \\
(\mathrm{CSt})\end{array}$ & $\begin{array}{c}\text { Cetane } \\
\text { Index }\end{array}$ \\
\hline B100 & 856.96 & 4.5 & 52.51 \\
H-FAME a & 858.21 & - & - \\
H-FAME b & 859.19 & - & - \\
H-FAME c & 863.69 & 4.6 & 55.59 \\
H-FAME d & 864.43 & - & - \\
SNI 2015 & $850-890$ & $2.3-6.0$ & Min. 51 \\
\hline
\end{tabular}

Based on the results of physical properties, density of $\mathrm{H}-$ FAME product increased, this was because the FAME component bound to hydrogen. While the viscosity of the product increased due to the increasing number of saturated methyl ester components and partial hydrogenation. The breakdown of unsaturated bonds into saturated bonds will increase the oxidation stability of biodiesel but it decreases flow properties, so it is necessary to obtain optimum conditions for both parameters to meet the specification [6]. In addition, the cetane index increased after the partial hydrogenation reaction showed that the more saturated components of the FAME, the more cetane index of the FAME which indicated combustion quality.

Table 3.7 Conversion. Selectivity and Yield of Product

\begin{tabular}{|c|c|c|c|}
\hline Product & \% Conversion & \% Selectivity & \% Yield \\
\hline H-FAME c & 93.26 & 10.58 & 9.87 \\
\hline
\end{tabular}

The calculation of selectivity was based on the amount of addition of the methyl oleate component, since methyl oleate is the desired component by the partial hydrogenation reaction in biodiesel. If the FAME component gets saturated, it will cause a high viscosity of biodiesel thereby imparting the flow properties [6].

\section{Conclusion}

Palm H-FAME production through partially hydrogenation using $\mathrm{Ni} / \mathrm{C}$ catalyst under operating conditions of $120^{\circ} \mathrm{C}$ and 6 bar with $100: 5 \%$ wt catalyst in the stirred batch autoclave reactor decreased the iodine number which was the empirical measure of the number of unsaturated bonds from 91.78 to 82.38 (g$\mathrm{I}_{2} / 100 \mathrm{~g}$ ) with an increase of oxidation stability from 585 to 602 minutes. These conditions with activated Ni/C led to dominant yield of $10.58 \%$, conversion of $93.26 \%$, and selectivity of $9.87 \%$ of methyl oleate $(18: 1)$.

\section{References}

1. A. Demirbas, Prog. Energy Combust. Sci, 33, 1-18 (2007)

2. J. Xin, H. Imahara, S. Shiro, Fuel. 88 (2), 282-286 (2009)

3. Agarwal, A. Kumar, K. Deepak, Fuel Processing Technology, 106, 447-452 (2013)

4. G. Knothe, Some aspects of biodiesel oxidative stability. Fuel Process. Technol., 88 (7), 669-677 (2007)

5. Ministry of Forestry, Internal Report (2015)

6. S. Goto, M. Oguma, N. Chollacoop EAS-ERIA Biodiesel Fuel Trade Handbook, 28-38 (2010) 